\title{
Performance Enhancement of Double Pipe Heat Exchanger with Helical Fin and Vortex Generator using CFD
}

\author{
Yedukondalu Talakonda, B. Jayachandraiah, B. Chandra Mohana Reddy
}

\begin{abstract}
Transferring heat from one fluid to another fluid without losing of major energy is a challenging task in the food processing and other industries. Double Pipe Heat Exchanger (DPHE) are light capacity Heat Exchangers (HE) used for air and other gas applications. In the present work an attempt is made to enhance the heat transfer of DPHE with helical fins and vortex generator. The working fluids are air and steam (water vapour) along outer and inner pipes. The parameters considered are helix angles, i.e. $35^{\circ}, 40^{\circ}, \& 45^{\circ}$ and pitch size i.e. $80 \mathrm{~mm}, 75 \mathrm{~mm}$ and 70 mm, and a vertex generator. CATIA V5 and Autodesk CFD are used for modelling and analysis. It is found that $40^{\circ}$ angle helix fin $70 \mathrm{~mm}$ pitch along Delta Wing type (Triangular) vortex generator (VG) gives best performance.
\end{abstract}

Keywords : DPHE, Vortex generator, Autodesk CFD, Catia.

\section{INTRODUCTION}

The double-pipe heat exchanger is one of the simplest types of heat exchangers. This is a concentric tube construction. Flow in a double-pipe heat exchanger can be co-current or counter-current. DPHEs are capable of working with variety of fluids and conditions. The change in the geometry of the inner tube, adding shapes at the outside of the tube can increase the efficiency of DPHE. The present research finds better turbulence in flow of DPHE achieves best heat transfer rates.

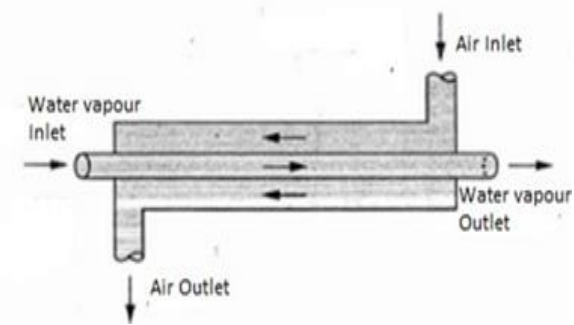

Fig. 1.Double Tube Heat Exchanger

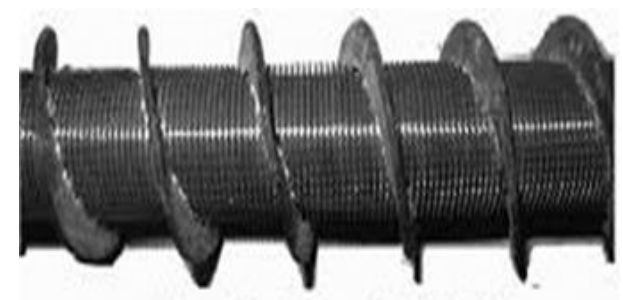

Fig. 2. Helical Fin on Inner Tube

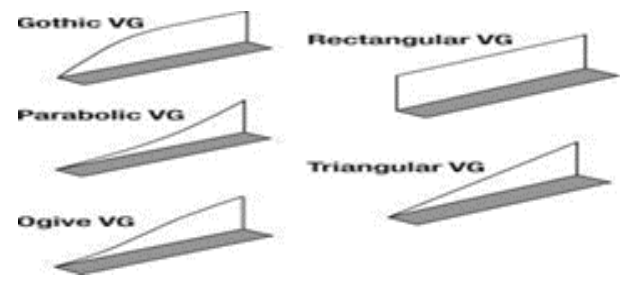

Fig. 3.Vortex Generators

\section{LITERATURE SURVEY}

A lot of work has been carried out by the researchers towards CFD and DPHE. New techniques and shapes of fins along the inner tube of DPHE are introduced. Some of the work carried is presented here. Shiva Kumar et. al [1], Mohan et. al [2], Qingang et.al [3] worked on performance of DPHE with hot fluid has made to flow through inner tubes and cold fluid is flow through the outer tubes. The simulations are carried out by using CATIA V5, Solid Works and leading CAD commercial software. Most of the researchers worked on ANSYS FLUENT for CFD analysis. Hae et.al [4], Mohan et.al [5], Seyed et.al [6], Mohamad Omidi et.al [7] worked on short helical fins, different pitches, nano fluids along with experimental, numerical, cfd simulations and empirical studies. 
The vast literature leads to the present investigation for the performance enhancement of DPHE with Autodesk Commercial CFD software with theoretical analysis.

\section{DATA COLLECTION}

From the vast literature survey and Tubular Exchanger Manufacturers Association (TEMA) standards the HE Model is designed. Most of the dimensions are taken from the standard cases. The following are the geometrical dimensions used for the design of DPHE.

Table- I: Geometrical Dimensions for DPHE

\begin{tabular}{|c|c|c|c|}
\hline S.No & Description & Unit & Value \\
\hline 1 & Heat Exchanger Length, $\mathrm{L}$ & $\mathrm{mm}$ & 920 \\
\hline 2 & Outer Pipe Inner Diameter, $\mathrm{D}_{\mathrm{i}}$ & $\mathrm{mm}$ & 48 \\
\hline 3 & Outer Pipe Outer Diameter, $\mathrm{D}_{0}$ & $\mathrm{~mm}$ & 50 \\
\hline 4 & Tube Length, 1 & $\mathrm{~mm}$ & 920 \\
\hline 5 & Inner Pipe Outer Diameter, $\mathrm{d}_{0}$ & $\mathrm{~mm}$ & 22 \\
\hline 6 & Inner Pipe Inner Diameter, $\mathrm{d}_{\mathrm{i}}$ & $\mathrm{mm}$ & 21 \\
\hline 7 & Helix Pitch, $\mathrm{P}_{\mathrm{t}}$ & $\mathrm{mm}$ & $70,75,80$ \\
\hline 8 & Helix Length & $\mathrm{mm}$ & 920 \\
\hline 9 & Helix Angle & $\mathrm{Deg}$ & $35,40,45$ \\
\hline 10 & Side Plate Diameter $\mathrm{D}_{\mathrm{sp}}$ & $\mathrm{mm}$ & 50 \\
\hline 11 & Side Plate Thickness, $\mathrm{T}_{\mathrm{sp}}$ & $\mathrm{mm}$ & 2 \\
\hline 12 & Helix Height & $\mathrm{mm}$ & 13 \\
\hline 13 & Triangular Vortex Generator & $\mathrm{mm}$ & $3 \times 3$ \\
& Dimensions & & \\
\hline
\end{tabular}

\section{MODELING}

Commercial CATIA V5 is used in the modelling of DPHE. All the individual parts are modelled separately and assembled. The helix angles and pitches are changed according to the requirement. Each and every model is designed and saved separately.

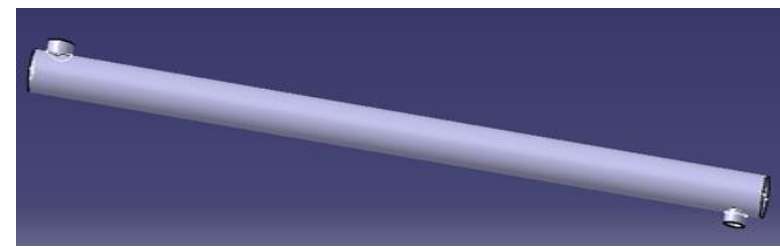

Fig. 4.Desing of Outer Pipe

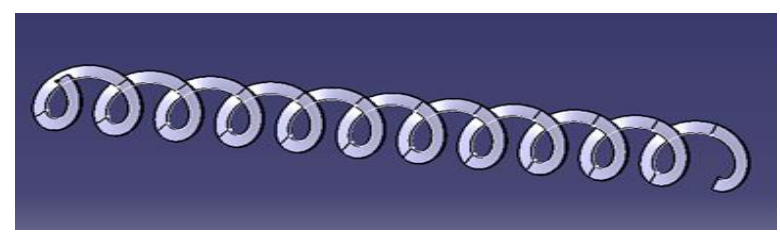

Fig. 5.Desing of Helix with an angle of 350

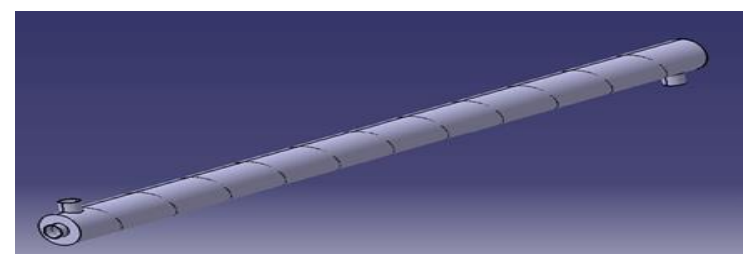

Fig. 6.Assembly Model of Inner Tube, Helix and Outer Tube on Heat Exchanger

\section{MESHING AND ANALYSIS}

Before going for the actual analysis the model is meshed using Autodesk CFD Simulation.

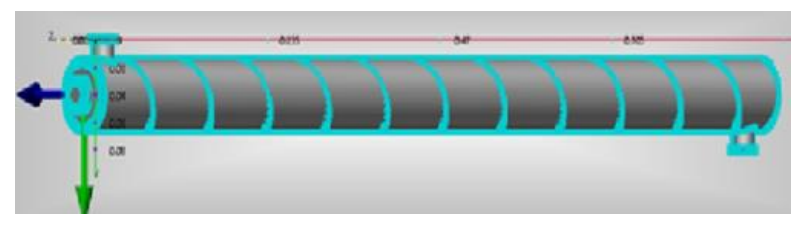

Fig. 7.Meshed Double Pipe Heat Exchanger

\section{A. CFD Governing Equations}

For CFD analysis the Governing Equations used Continuity equation: $\frac{\partial \rho}{\partial \mathrm{t}}+\operatorname{div}(\rho \mathrm{u})=0$

Momentum Equation:

Stress components in $\mathrm{x}$ - direction

$\frac{\partial \mathrm{Du}}{\mathrm{Dt}}=\frac{\partial\left(-\mathrm{p}+\tau_{\mathrm{xx}}\right)}{\partial \mathrm{x}}+\frac{\partial \tau_{\mathrm{yz}}}{\partial \mathrm{y}}+\frac{\partial \tau_{\mathrm{zx}}}{\partial \mathrm{z}}+\mathrm{S}_{\mathrm{Mx}}$

$\mathrm{Y}$ - Component of the momentum equation

$\frac{\rho D v}{D t}=\frac{\partial \tau_{x y}}{\partial x}+\frac{\partial\left(-p+\tau_{y y}\right)}{\partial y}+\frac{\partial \tau_{z y}}{\partial z}+S_{M y}$

$Z$-Component of the momentum equation

$$
\frac{\rho D w}{D t}=\frac{\partial \tau_{x z}}{\partial x}+\frac{\partial \tau_{y x}}{\partial y}+\frac{\partial\left(-p+\tau_{z z}\right)}{\partial z}+S_{M z}
$$

\section{Energy Equation}

Rate of increase of energy $=$ Net rate of heat added to fluid particle + Net rate of work done on fluid particle

\section{B. Materials}

Table- II: Material Properties

\begin{tabular}{|c|c|c|c|c|}
\hline \multirow{2}{*}{ S.No } & Materials & $\begin{array}{c}\text { Density } \\
\left(\mathrm{Kg}^{3} \mathrm{~m}^{3}\right)\end{array}$ & $\begin{array}{c}\text { Specific } \\
\text { Heat } \\
(\mathrm{kJ} / \mathrm{kgK})\end{array}$ & $\begin{array}{c}\text { Therm al } \\
\text { Conductivity } \\
\left(\mathrm{W} / \mathrm{m}^{2} \mathrm{~K}\right)\end{array}$ \\
\hline 1 & $\begin{array}{c}\text { Hot Liquid } \\
\text { (Water Vapour) }\end{array}$ & 958.4 & 1.8882 & 0.02556 \\
\hline 2 & $\begin{array}{c}\text { Cold Fluid } \\
\text { (Air) }\end{array}$ & 997.4 & 0.1004 & 0.02563 \\
\hline 3 & $\begin{array}{c}\text { Pipe } \\
\text { (Red Coper) }\end{array}$ & 8940 & 0.39 & 385 \\
\hline 4 & $\begin{array}{c}\text { Helical Fin } \\
\text { (Red Copper) }\end{array}$ & 8940 & 0.39 & 385 \\
\hline 5 & $\begin{array}{c}\text { Vortex } \\
\text { Generator } \\
\text { (Red Copper) }\end{array}$ & 8940 & 0.39 & 385 \\
\hline
\end{tabular}

\section{Boundary Conditions}

The input conditions considered for this work are inlet_temp and inlet velocities for the fluids. The inlet velocities for water vapour \& cold air are $19462.15 \mathrm{~mm} / \mathrm{sec}$ \& $13269.61 \mathrm{~mm} / \mathrm{sec}$. The inlet temperatures are $100{ }^{\circ} \mathrm{C} \&$ $25{ }^{0} \mathrm{C}$ for water vapour and air. The outlet pressure is considered to be zero gauge pressure, because outlet pressure is considered to be atmospheric pressure. 


\section{Model Calculations}

Hot fluid heat transfer rate $\left(\mathrm{Q}_{\mathrm{h}}\right)$ :

$Q_{h}=m_{h} C_{p h}\left(T_{h i}-T_{h o}\right) \quad \mathrm{W}$

Cold fluid heat transfer rate $\left(\mathrm{Q}_{\mathrm{c}}\right)$ :

$Q_{c}=m_{c} C_{p c}\left(T_{c o}-T_{c i}\right) \quad \mathrm{W}$

Average value of heat transfer rate $\left(\mathrm{Q}_{\mathrm{avg}}\right)$

$Q_{\text {avg }}=\left(Q_{h}+Q_{c}\right) / 2 \mathrm{~W}$

Logarithmic mean temperature difference (LMTD):

$\operatorname{LMTD}\left(\Delta T_{l m}\right)=\left(\frac{\left(T_{h i}-T_{c o}\right)-\left(T_{h o}-T_{c i}\right)}{\ln \left(\frac{T_{h i}-T_{c o}}{T_{h o}-T_{c i}}\right)}\right)$ (9)

Surface Area(As):

$A_{s}=\pi D_{o} L \quad \mathrm{~m}^{2}$

Overall Heat Transfer Coefficient $\left(\mathrm{U}_{0}\right)$

$$
\begin{aligned}
& Q_{\text {avg }}=U_{o} A_{s} \Delta T_{l m} \\
& U_{o}=\frac{Q_{\text {avg }}}{A_{s} \Delta T_{l m}}
\end{aligned}
$$

\section{RESULTS}

The results of DPHE along Helical fins with and without VG are presented below. The CFD results provides better values of heat transfer rate, $\mathrm{X}, \mathrm{Y} \& \mathrm{Z}$ - velocity, continuity, $\mathrm{k}-\varepsilon$, energy are the part of scaled residual which have to converge in the control volume.

\section{A. Double Pipe Heat Exchanger without Fin}

\section{a. Temperature Contour}

The DPHE without Helical Fins shown as follows. The inlet Temperature of Water Vapour in Inner Pipe of Heat Exchanger is $100{ }^{\circ} \mathrm{C}$ and in outlet it decreased to $83.0767^{\circ} \mathrm{C}$. In the case of cold Air inlet Temperature was $25{ }^{\circ} \mathrm{C}$ and the outlet Temperature is increased to $59.3591{ }^{\circ} \mathrm{C}$.

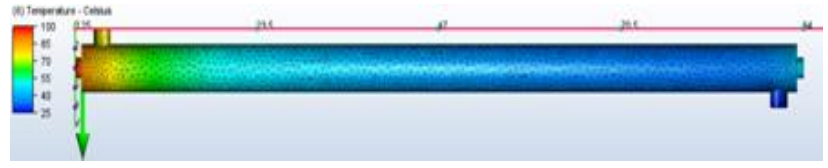

Fig. 8.Temperature Distribution Without Fin in DPHE

\section{b. Velocity Contour}

The Velocity profile of inner pipe at inlet is $19462.15 \mathrm{~mm} / \mathrm{s}$ and in outlet it is $10699.9097 \mathrm{~mm} / \mathrm{s}$. In the case of outer pipe at inlet is $10269.61 \mathrm{~mm} / \mathrm{s}$ and in outlet it is $12312.8298 \mathrm{~mm} / \mathrm{s}$.

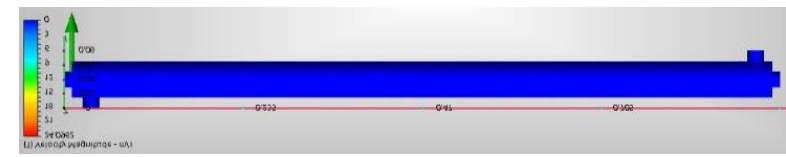

Fig. 9.Velocity contour of DPHE without Fin

\section{B. DPHE with $35^{\circ}$ Helix angle and $80 \mathrm{~mm}$ Pitch Size}

\section{a. Temperature Contour}

The outlet temp. of Water Vapour in Inner Pipe of Heat Exchanger is decreased to $78.362^{\circ} \mathrm{C}$. In case of cold air outlet Temperature is increased to $75.5893^{\circ} \mathrm{C}$.

\section{b. Velocity Contour}

The Velocity of Inner pipe at inlet is $11923.7424 \mathrm{~mm} / \mathrm{s}$. In the case of outer pipe the outlet at velocity is $11119.4333 \mathrm{~mm} / \mathrm{s}$.

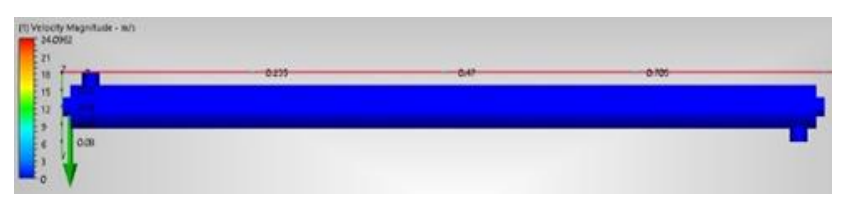

Fig. 11. Velocity Contour for $35^{\circ}$ helical fin

\section{DPHE with $40^{\circ}$ Helix angle and $80 \mathrm{~mm}$ Pitch Size}

\section{a. Temperature Contour}

Temperature of the Water Vapour in DPHE at outlet is decreased to $75.6807^{\circ} \mathrm{C}$. At the outlet the temperature of cold air is increased to $78.4347^{\circ} \mathrm{C}$.

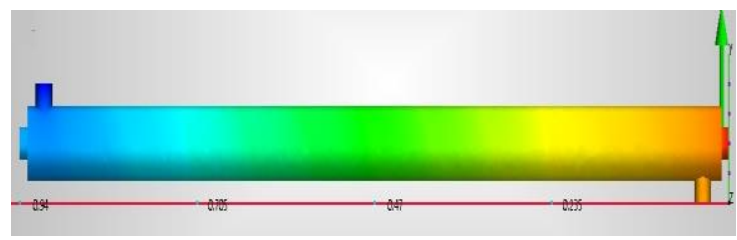

Fig. 12. Temperature Distribution for $40^{\circ}$ helical fin

\section{b. Velocity Contour}

The profile of Inner pipe, at outlet is $10709.4388 \mathrm{~mm} / \mathrm{s}$ and at outer pipe outlet is $12377.278 \mathrm{~mm} / \mathrm{s}$.

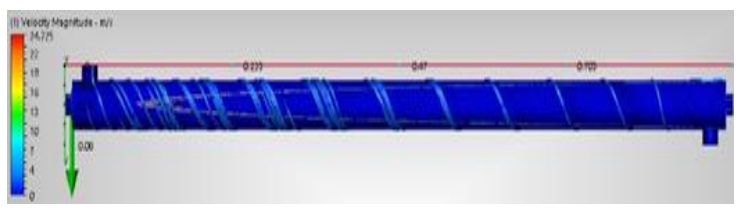

Fig. 13. Velocity Contour for for $\mathbf{4 0}^{\circ}$ helical fin D. DPHE with $45^{\circ}$ Helix angle and $80 \mathrm{~mm}$ Pitch Size

\section{a. Temperature Contour}

Temperature of the Water Vapour at outlet is decreased to $78.2782{ }^{\circ} \mathrm{C}$. For air, the outlet Temperature is increased to $75.5044{ }^{\circ} \mathrm{C}$

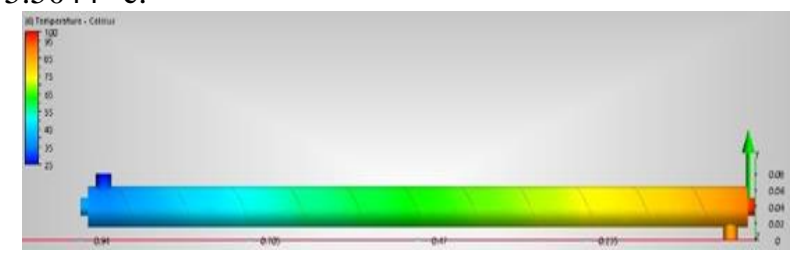

Fig. 14. Temperature Distribution for $45^{\circ}$ helical fin

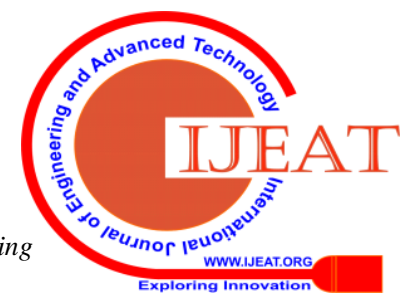




\section{b. Velocity Contour}

The Velocity at inner pipe is $11901.0231 \mathrm{~mm} / \mathrm{s}$. For outer pipe, at outlet the velocity is $1237.7278 \mathrm{~mm} / \mathrm{s}$.

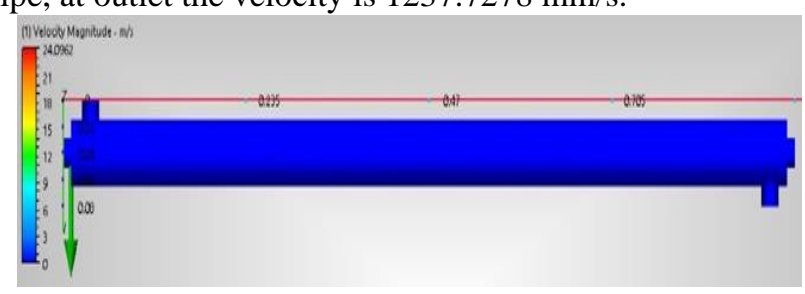

Fig. 15. Velocity Contour for $45^{0}$ helical fin

After considering these cases, the following results are obtained.

Table- III: Temperature \& Velocity Results

\begin{tabular}{|l|c|c|c|c|c|c|c|c|}
\hline \multirow{2}{*}{ S.Ale } & \multirow{2}{*}{$\begin{array}{c}\text { Helix } \\
\text { Angle }(\theta)\end{array}$} & \multirow{2}{*}{$\begin{array}{c}\text { Pitch } \\
\text { Sizes } \\
(\mathrm{mm})\end{array}$} & \multicolumn{2}{|c|}{$\begin{array}{c}\text { Air Temperature } \\
\left({ }^{\circ} \mathrm{C}\right)\end{array}$} & \multicolumn{2}{c|}{$\begin{array}{c}\text { Water Vapour } \\
\text { Temperature } \\
\left({ }^{\circ} \mathrm{C}\right)\end{array}$} & \multicolumn{2}{|c|}{$\begin{array}{c}\text { Velocity } \\
(\mathrm{mm} / \mathrm{sec})\end{array}$} \\
\cline { 4 - 9 } & & & In let & Out let & In let & Out let & Air & $\begin{array}{c}\text { Water } \\
\text { Vapour }\end{array}$ \\
\hline 1. & 35 & 80 & 25 & 75.5893 & 100 & 78.362 & 13269.61 & 19462.15 \\
\hline 2. & 40 & 80 & 25 & 78.4347 & 100 & 75.6807 & 13269.61 & 19462.15 \\
\hline 3. & 45 & 80 & 25 & 75.5044 & 100 & 78.2782 & 13269.61 & 19462.15 \\
\hline
\end{tabular}

From the above table it is clear that $40^{\circ}$ helix angle gives the best heat transfer rate and selected for the analysis with different pitch sizes.

\section{E. DPHE with $40^{\circ}$ Helix angle and $75 \mathrm{~mm}$ Pitch Size}

\section{a. Temperature Contour}

Temperature of the Water vapour at outlet is decreased to $75.6324^{\circ} \mathrm{C}$. For cold air the outlet the Temperature increased to $78.8363^{\circ} \mathrm{C}$

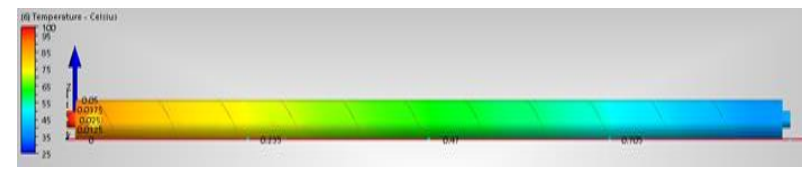

Fig. 16. Temperature Distribution for $75 \mathrm{~mm}$ pitch at $40^{\circ}$ helical fin

\section{b. Velocity Contour}

The Velocity at the inner pipe outlet is $10724.563 \mathrm{~mm} / \mathrm{s}$. In the case of outer pipe, velocity at outlet is $12357.458 \mathrm{~mm} / \mathrm{s}$.

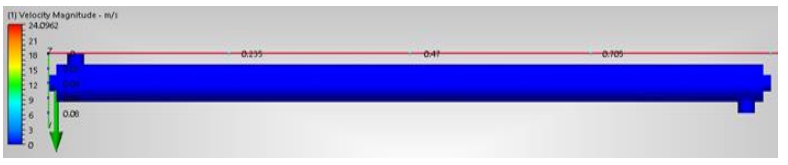

Fig. 17. Velocity Contour for $75 \mathrm{~mm}$ pitch at $40^{\circ}$ helical fin

\section{F. DPHE with $40^{\circ}$ Helix angle and $70 \mathrm{~mm}$ Pitch Size}

\section{a. Temperature Contour}

Temperature of the water vapour at outlet it decreased to $75.5841^{\circ} \mathrm{C}$. and cold air outlet the temperature increased to $79.2379{ }^{\circ} \mathrm{C}$.

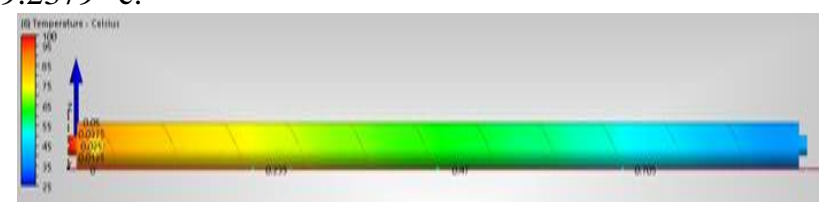

Fig. 18. Temperature Distribution for $70 \mathrm{~mm}$ pitch at $40^{\circ}$ helical fin

\section{b. Velocity Contour}

The Velocity of inner pipe at outlet is $10742.2639 \mathrm{~mm} / \mathrm{s}$ and for outer pipe it is $12330.2743 \mathrm{~mm} / \mathrm{s}$.

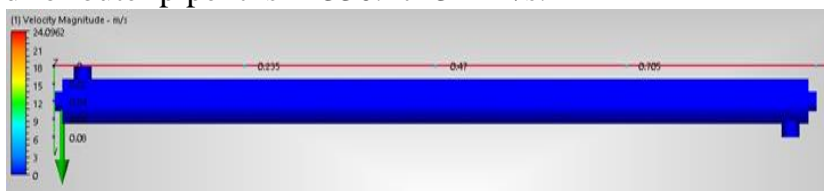

Fig. 19. Velocity Contour for $70 \mathrm{~mm}$ pitch at $40^{\circ}$ helical fin

The results are tabulated as follows.

Table- IV: Temperature \& Velocity Results

\begin{tabular}{|l|c|c|c|c|c|c|c|c|}
\hline \multirow{2}{*}{ S.Ne } & \multirow{2}{*}{$\begin{array}{c}\text { Helix } \\
\text { Angle }(\theta)\end{array}$} & & \multicolumn{2}{|c|}{$\begin{array}{c}\text { Air Temperature } \\
\left({ }^{\circ} \mathrm{C}\right)\end{array}$} & \multicolumn{2}{|c|}{$\begin{array}{c}\text { Water Vapour } \\
\text { Temperature }\left({ }^{\circ} \mathrm{C}\right)\end{array}$} & \multicolumn{2}{|c|}{ velocity $(\mathrm{mm} / \mathrm{sec})$} \\
\cline { 5 - 9 } & & Sizes & In let & Out let & In let & Out let & Air & $\begin{array}{c}\text { Water } \\
\text { Vapour }\end{array}$ \\
\hline 1. & 40 & 80 & 25 & 75.5893 & 100 & 78.362 & 13269.61 & 19462.15 \\
\hline 2. & 40 & 75 & 25 & 78.4347 & 100 & 75.6807 & 13269.61 & 19462.15 \\
\hline 3. & 40 & 70 & 25 & 75.5044 & 100 & 78.2782 & 13269.61 & 19462.15 \\
\hline
\end{tabular}

From the above results it is clear that $40^{\circ}$ helix angle gives better heat transfer with $70 \mathrm{~mm}$ pitch. So, $40^{\circ}$ helix angle and $70 \mathrm{~mm}$ pitch size is considered for further investigation with Vortex Generators.

\section{G. DPHE with $40^{\circ}$ Helix angle and $70 \mathrm{~mm}$ Pitch Size with VG}

\section{a. Temperature Contour}

Temperature of the water vapour at outlet is decreased to $76.0362{ }^{\circ} \mathrm{C}$ and cold air outlet the temperature increased to $77.6729{ }^{\circ} \mathrm{C}$.

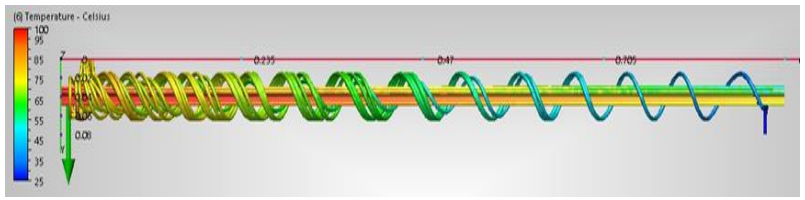

Fig. 20. Temperature Distribution for $40^{\circ}$ fin with VG

\section{b. Velocity Contour}

The velocity of inner pipe outlet is $11887.4818 \mathrm{~mm} / \mathrm{s}$. and outer pipe outlet velocity is $11112.8558 \mathrm{~mm} / \mathrm{s}$.

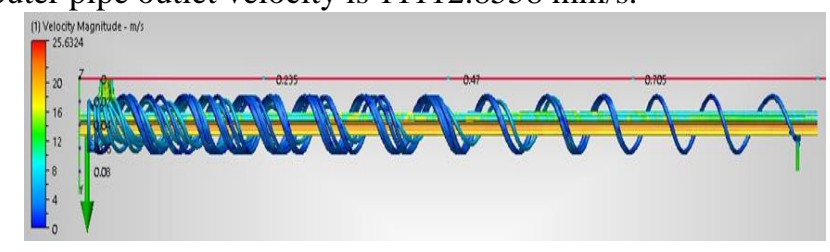

Fig. 21. Velocity Contour for $40^{\circ}$ fin with VG

\section{DISCUSSION}

All the results are tabulated as below for the better understanding of the performance of the DPHE. 
Table- V: Temperature \& Velocity Results

\begin{tabular}{|c|c|c|c|c|c|c|c|}
\hline SNe & $\begin{array}{c}\text { Types of } \\
\text { Converged } \\
\text { Design }\end{array}$ & $\begin{array}{c}\text { Helix } \\
\text { Angle } \\
\text { (degrees) }\end{array}$ & $\begin{array}{l}\text { Pitch } \\
\text { Sizes } \\
(\mathrm{mm})\end{array}$ & $Q_{x x z}(W)$ & LMTD & $\begin{array}{c}\text { Surface } \\
\text { Area }\left(\mathrm{m}^{2}\right)\end{array}$ & $\begin{array}{c}\text { Overall Heat } \\
\text { Transfer } \\
\text { Coefficient } \\
\left(\mathrm{W} / \mathrm{m}^{2}{ }^{\circ} \mathrm{C}\right)\end{array}$ \\
\hline 1 & Tube in tube & - & 80 & 150.2561 & 48.841 & 0.14452 & 21.2883 \\
\hline 2 & \multirow{5}{*}{ Helical Fins } & $35^{\circ}$ & 80 & 207.3503 & 34.088 & 0.26282 & 23.1444 \\
\hline 3 & & $40^{\circ}$ & 80 & 224.8986 & 36.986 & 0.26472 & 25.1365 \\
\hline 4 & & $45^{\circ}$ & 80 & 213.8842 & 35.172 & 0.27293 & 24.1686 \\
\hline 5 & & $40^{\circ}$ & 70 & 227.2023 & 37.365 & 0.27732 & 25.9138 \\
\hline 6 & & $40^{\circ}$ & 75 & 226.0483 & 37.176 & 0.28432 & 25.3367 \\
\hline 7 & $\begin{array}{c}\text { Delta Wing } \\
\text { Type Vortex } \\
\text { Generator }\end{array}$ & $40^{\circ}$ & 70 & 231.13805 & 38.023 & 0.29283 & 27.1305 \\
\hline
\end{tabular}

\section{A. Graphs}

\section{a. Overall Heat Transfer Coefficient vs Helix Angle}

The following graph plotted between Helix Angle and overall heat transfer coefficient. This shows an increase in overall heat transfer in $40^{\circ}$ helix angle than the tube in tube heat exchanger.

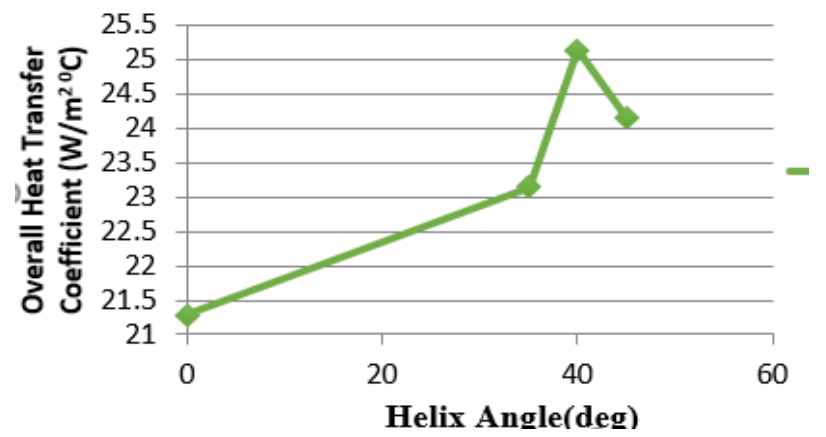

Fig. 22. Helix angle vs overall heat transfer coefficient

\section{b. Overall Heat Transfer Coefficient vs Helix Angle}

This shown an increase in overall heat transfer in $40^{\circ}$ helix angle and $70 \mathrm{~mm}$ pitch size and vortex generator than the tube in tube heat exchanger.

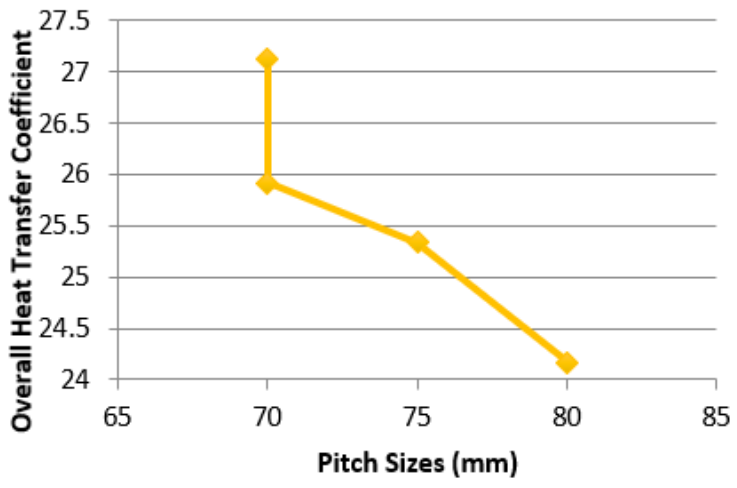

Fig. 23. Helix angle vs overall heat transfer coefficient

\section{CONCLUSION}

A DPHE is modelled and simulated using Catia V5 and Auto desk Simulation Software. Mass flow rate and inlet temperatures of the fluids are the boundary conditions. Analysis carried-out for different operating conditions.

Simple DPHE is taken to the reference for the evaluation of enhancement of the heat exchanger. Helical fin is placed on the outer surface of the inner pipe with constant pitch of 80 $\mathrm{mm}$ with different helical angles i.e. $35^{\circ}, 40^{\circ}, 45^{0}$. From the analysis it is found $40^{\circ}$ with $80 \mathrm{~mm}$ gives better performance.

Form the results, it is considered $40^{\circ}$ helical angle with different pitches i.e. $70 \mathrm{~mm}, 75 \mathrm{~mm}$ and $80 \mathrm{~mm}$ and found $40^{0}$ with $70 \mathrm{~mm}$ gives the best performance. Finally a triangular vortex generator is provided for the $40^{\circ}$ helix angle with $70 \mathrm{~mm}$ pitch size of heat exchanger. Better results are observed in the final case with vortex generators.

It is found that the heat transfer enhanced by the heat exchanger with $70 \mathrm{~mm}$ pitch with $40^{\circ}$ helical angle is about $142-145 \%$ than the simple DPHE without fin.

The heat transferred in DPHE enhanced with vortex generator is $148-153 \%$ more than that transferred by the DPHE without fin.

Th present work concludes that heat transfer at the shell side increased by helical fins and vortex generators. This shown the importance of VGs in heat transfer enhancement.

\section{REFERENCES}

1. Shiva Kumar, K. Vasudev Karanth and Krishna Murthy, "Numerical study of heat transfer in a finned double pipe heat exchanger", World Journal of Modelling and Simulation, Vol. 11 (2015) No. 1, pp. 43-54, ISSN 1 746-7233, England, UK.

2. Mohan,P.Sankar Ganesh, S.Ramesh, M.Sathish, "CFD Analysis Of Double Pipe Heat Exchanger With And Withoutdimples", International Research Journal of Engineering and Technology (IRJET), Volume: 05 Issue: 10| Oct2018.

3. Qingang Xiong, M. Jafaryar, Alireza Divsalar, M. heikholeslami, Ahmad Shafee, Dat D. Vo, Muhammad Humran Khan, I. Tlili, Zhixiong L, "Macroscopic simulation of nanofluid turbulent flow due to compound turbulator in a pipe", Chemical Physics 527 (2019) 110475.

4. Tae-Hyun Chang, Kwon-Soo Lee, Ki-Won Chang, Sang Min Kim and Chang-Hoan Lee, "Heat transfer characteristics of a short helical plate in a horizontal circular tube", Journal of Mechanical Science and Technology 33 (8) (2019) 1-8, DOI 10.1007/s12206-019-0701-7.

5. T.Mohankumar, Dr.K.Rajan, K.Sivakumar,V.Gopal, "Experimental Analysis of Heat transfer Characteristics of Heat Exchanger Using Nano Fluids", Materials Science and Engineering 574 (2019) 012011, doi:10.1088/1757-899X/574/1/012011.

6. Seyed Shahab Mozafarie, Kourosh Javaherdeh, "Numerical design and heat transfer analysis of a non-Newtonian fluid flow for annulus with helical fins", Engineering Science and Technology, an International Journal, https://doi.org/10.1016/j.jestch.2019.03.001.

7. Mohamad Omidi, A. Ali Rabienataj Darzi, Mousa Farhadi, "Turbulent heat transfer and fluid flow of alumina nanofluid inside three-lobed twisted tube", Journal of Thermal Analysis and Calorimetry, https://doi.org/10.1007/s10973-019-08026-w (2019).

\section{AUTHORS PROFILE}

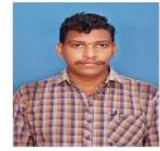

Yedukondalu Talakonda is pursuing his full time $\mathrm{Ph} . \mathrm{D}$ in mechanical engineering at JNT University, Ananthapuramu. His research areas are Heat Exchangers, CFD, FEM and Machine Design.

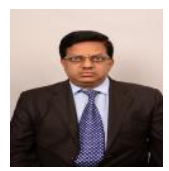

Dr. B. Jayachandraiah is Professor in the department of mechanical engineering, Srikalahastheeswara Institute of Technology, Srikalahasti. He received his Ph.D from the Jawaharlal Nehru Technological University, Hyderabad. He has an enormous 27 years' experience in the field of teaching and 18 years in research. He awarded 10 Master Degrees in Mechanical Engineering. He published more than 85 research papers in reputed international, national journals and conferences. Presently he is supervising $3 \mathrm{Ph}$. D Scholars. His areas of interest are CFD, FEM and Heat Transfer. 
Dr. B. Chandra Mohana Reddy is Head and Associate professor of mechanical engineering in CEA, JNT University, Ananthapuramu. He received his $\mathrm{Ph}$. D in mechanical engineering. He has a vast experience of 27 years in teaching and research with 7 years industry.

Presently he is supervising UG, PG and Ph.D Scholars in various advanced research problems. He published more than 80 research articles in reputed international, national journals and conferences. His areas of interest are Production, Industrial Engineering and Design. 